\title{
The Influence of Psycho-Social Environment and Socio-Economic Status on Early Language Development Among Toddlers
}

\section{Bardha Kika}

\begin{abstract}
Learning to talk is one of the most visible and important achievements of early childhood (Rvachew, 2015). Language skills, in particular, are critical to children's adjustment in school and in later life (Benner, Nelson, Ron, Epstein, 2002). There is evidence to suggest that children with language problems may develop social, emotional,and behavioral problems (Schoon, Parsons, \& Rush, 2010). In the literature, the environment with all its complexities it is mentioned as one of the most influential factor for the language development (Johnston, 2010). However, most of the studies that treated this aspect have been conducted in developed countries and less is known whether the pattern of influence is the same among other underrepresented study population. This study is focused on identification of the role of the environment on the toddlers' language development in a low-income country, such as Kosovo. In total, 201 randomly selected parents (55\% males) from three kindergartens in Kosovo were interviewed for this study. We used the Communication and Symbolic Behavior Scales Developmental Profile (CSBS DP; Wetherby\&Prizant, 2002) to collect the data and a demographic questionnaire to identify the characteristics of the environment. The preliminary results show a positive correlation between parental education and toddlers' language development $(r=.19, p<.01)$. Moreover, a positive correlation was found between socio-economic status and toddlers' language $(r=.21, p<.05)$. Importantly, it was found that there are significant differences between toddlers' language that frequent kindergarten and the group of toddlers that do not frequent early education institution. The present finding goes into the same line with other studies that confirm environment as important factor on language acquisition. Not only parent's education, but also the economic status is shown to play a major role on language development. Most importantly, it is shown that along with family kindergarten influences the toddler language skills. These results that attend kindergarten have significantly higher language skills. This can serve to develop intervention programs in Kosovo, to raise awareness among general population for the importance of the early education attendance, which currently is less than $10 \%$.
\end{abstract}

Keywords: language development, socio-economic status, the role of environment. 